the 19th century, evolved into what became recognised as the psychiatric asylums. He argues that the category of 'unreason' included a variety of people identified by such things as poverty, prostitution, homosexuality, criminality and 'madness', the last being an undifferentiated category and bearing an uncertain relation to scholarly conceptions of mental illness. The arrival and engagement of doctors in institutions of confinement, argued Foucault, had nothing to do with psychiatric expertise and much to do with public fears and the exercise of authority. Public fears included those of infection spreading from the institutions to nearby populations. The need for authority became acute following the French Revolution, when King and Church lost theirs. As to Philippe Pinel's legendary fame for removing the chains from his patients, Foucault puts forward complex social theories and processes as to why this happened and challenges narratives that attribute it to medical benevolence and enlightenment.

Readers with an interest in the history of psychiatry can make their own minds up about competing or complementary explanations but psychiatrists will do well to be aware of Foucault's scepticism about the history of our profession, while at the same time reflecting on the balance of cynicism and idealism in human affairs and remaining appropriately and severely critical of his romanticising of 'madness'.

The authors of the paper on mental health law in Ireland remind us of the all too real need for services for people with mental health problems. They seem to endorse views put forward by
Amnesty International (2010) that laws intended to protect the liberty of people with mental health problems may need to be complemented by laws to specify, develop and constantly improve services to this population and argue that such is the case in Ireland. In his foreword to the Amnesty International (2010) document, L. O. Gostin writes:

For the majority of people, the words 'mental health and human rights' bring to mind issues around liberty, privacy, bodily integrity and non-discrimination. The right to adequate mental health service is often overlooked, but it is an essential component of the human right to health. So too do human rights require governments to provide mental health services in ways that are transparent, cost effective, and accountable. By providing supports and services in the community, States can enable people to realise their right to live and participate in the community and avoid the social exclusion and discrimination that destroys so many lives.

The need for practical follow-through is also highlighted by the paper on Portugal. This country is reported to have made significant progress in legislation and service development. The almost complete lack of data on implementation reported by Almeida and Molodynski is deeply troubling nevertheless. Is the law applied as intended? Has it made a difference to how people are compulsorily treated? Are there opportunities to improve practice further?

\section{References}

Amnesty International (2010) Legislating for Change: Accountability and Reform of Our Mental Health Services. Existing Law in Ireland. Available at http://www.amnesty.ie/sites/default/files/Legislating \% 20 for \% 20Change.pdf (accessed December 2015).

Foucault, M. (2006) History of Madness. Routledge.
MENTAL HEALTHLAW PROFILE

\title{
The new French mental health law regarding psychiatric involuntary treatment
}

\author{
Jean Louis Senon, ${ }^{1}$ Carol Jonas ${ }^{2}$ and Michel Botbol ${ }^{3}$
}

In memoriam Carol Jonas

'Professor of Psychiatry, Poitiers University and Henri Laborit University Hospital, Poitiers, France

2Public Psychiatrist, CHU Tours, France

3Professor of Child and Adolescent Psychiatry, University of Western Brittany and Brest University Hospital, Bohars,

France, email michel.botbol@ France, emal
chu-brest.fr
The French Republic has had four laws governing the detention of people with a mental illness. The first dates from 1838 and remained in place until 1990. The most recent one was issued on 27 September 2013; it confirmed the role of the judge and strengthened the legal procedures. This new French mental health law is an attempt to find a balance between the protection of patients' rights and the need for treatment.

On 27 September 2013 France enacted a new mental health law regarding psychiatric involuntary treatment. It is the fourth French mental health law on this matter. The first was issued on 30 June 1838 under the influence of Esquirol, Pinel's pupil and the father of French psychiatry. This historic law was replaced only on 27 June 1990, after several previous attempts, unsuccessful because of the advantages seen by many in the 1838 law and because of the difficulties in dealing with involuntary treatments in a democratic country. A new law was then issued on 5 July 2011. It introduced an important innovation: the supervision of the limitation of liberty imposed by psychiatric involuntary treatment was shifted from the administrative authority (the prefect, a local representative of the state) to a judge (the Judge of Liberties and Detention). The last law was issued 
on 27 September 2013 and confirmed the role of the judge in this control, strengthening the importance of legal procedures in this task.

\section{The judicial context of the law of 27 September 2013}

As in other democratic countries, this law had to comply with the country's constitution and the international conventions ratified by the French parliament. The European Convention on Human Rights (ECHR) was very influential in the elaboration of this law. The Convention's main objective is to protect the individual freedom of European citizens and to control how a state can justify any limitations on freedom it imposes. To reduce the risk of arbitrary decisions, the ECHR imposes judicial control on the limitation of rights by psychiatric involuntary treatment, a disposition with which France did not comply before 2011. The ECHR states that judicial control should be possible at any time and, if needed, repeatedly. Every patient should be able to access judicial review quickly. The ECHR describes in detail the patient's rights, insisting on the right to information and on the principle of restricting any limitation to liberty to the least needed to allow the necessary psychiatric treatment.

The French constitution was the second strong determinant of the 2011 and 2013 French mental health laws. In 2010 and 2011, the Constitutional Council (the equivalent of the UK Supreme Court) laid down major decisions on this topic. In these rulings the Council decided that the law makers had to reconcile, on the one hand, the protection of the health of patients who are mentally ill and the prevention of public order disturbances (including violence to others) crucial for the preservation of constitutional rights and, on the other hand, the protection of constitutional personal rights (QPC decision number 2010-71 of 26 November 2010, 2011-135 of 9 June 2011, 2011-174 of 6 October 2011, 2011-185 of 21 October 2011 and article L 3211-3 of the Public Health Code; see http://www. conseil-constitutionnel.fr).

\section{The three types of involuntary treatment introduced by the law of 27 September 2013}

Three types of involuntary treatment are permitted (Senon et al, 2012a):

- psychiatric involuntary treatment by decision of a hospital director at the request of a third party or, without this request, in case of extreme urgency (imminent peril)

- psychiatric involuntary treatment at the request of a representative of the state

- involuntary out-patient treatment.

\section{Decision of a hospital director}

This procedure is used when a patient is diagnosed with a mental disorder needing psychiatric treatment associated with continuous custody (full-time hospitalisation) and when, because of this mental disorder, the patient is not able to give consent to that treatment. The usual procedure used in these cases is to find a third party who can decide on the patient's behalf (that is to say, in the logic of the French mental health law, to decide in the patient's interest as the patient would if not impaired by the mental disorder). This type of procedure is called psychiatric treatment at the request of a third party (soins psychiatriques a la demande d'un tiers). In this case, the law requires six certificates: two initial certificates, one certificate after the first 24 hours, one certificate of somatic medical examination, one certificate after the first 72 hours, and one certificate of referral to the Judge for Liberties and Detention.

When no third party is available, the law introduces the possibility of using a procedure unprecedented in France: psychiatric involuntary treatment can be decided by the hospital director without any third-party request, but for a limited period (72 hours).

\section{Request of a representative of the state}

The representative in question is generally the 'prefect' of the department (the middle level of local government). For this procedure three criteria are required in relation to the patient (Senon et al, 2012b):

- the presence of a mental disorder

- a need for treatment

- a behaviour compromising the person's safety or seriously threatening public order.

The initial medical certificate has to be issued by a psychiatrist external to the hospital in which the patient will be hospitalised. This certificate has to describe the disorder and give enough evidence to support the fact that it compromises the person's safety or seriously threatens public order. The local state representative officer has to issue authorisation for this procedure. The 24-hour and 72-hour certificates have to be made by the hospital psychiatrist in charge of the patient's treatment. Between the fifth and the eighth days of the hospitalisation, a certificate has to be made by this psychiatrist to confirm the procedure for a hearing by the Judge for Liberties and Detention at the 12th day of the hospitalisation. These certificates have then to be issued monthly.

The law also introduces the possibility in extreme urgency of this type of psychiatric treatment by decision of the city's mayor. In this case the proceeding is grounded on the mayor's authorisation ordering a provisional hospitalisation. Here again, a detailed medical certificate has to assert that the patient's mental disorder needs treatment and compromises the person's safety or seriously threatens public order.

\section{Involuntary out-patient treatment}

The 5 July 2011 law introduced the possibility of psychiatric involuntary treatment on the basis of 
a treatment plan proposed by the treating psychiatrist. This plan has to detail the treatment modalities (day hospital and other out-patient treatments), their frequency and their type. This treatment plan has to be written in reasonable detail but it does not include commitments that are unduly burdensome to the patient's treatment team. However, the use of force to give medication is not permitted in community clinics or other community settings. The treatment plan has to be modified each time a substantial change is implemented in the patient's treatment. It has to be elaborated by the psychiatrist at the hospital in which the patient has been hospitalised at the first stage of treatment.

\section{Conclusion}

The law of 27 September 2013 represents a new step in psychiatric involuntary treatment in France. One of its main characteristics is to introduce the Judge for Liberties and Detention in the control of treatment without the patient's consent, shifting to judicial power what was previously an administrative power (Senon \& Voyer, 2012). Indeed, it gives to the judge the task of checking if the limitations on individual liberties imposed by the psychiatric involuntary treatment are well adapted to and commensurate with the patient's therapeutic needs. Decisions of the French Constitutional Council allow the French mental health law to comply with the European recommendations.

\section{References}

Senon, J. L. \& Voyer, M. (2012) Modalités et impact de la mise en oeuvre de la loi du 5 juillet 2011: de l'impérieuse nécessité de placer le patient au centre de nos préoccupations. Annales Médicopsychologiques, 170, 693-698.

Senon, J. L., Jonas, C. \& Voyer, M. (2012a) Les soins sous contrainte des malades mentaux depuis la loi du 5 juillet 2011 'relative aux droits et à la protection des personnes faisant l'objet de soins psychiatriques et aux modalités de leur prise en charge'. Annales Médico-psychologiques, 170, 211-221.

Senon J. L., Leturmy, L. \& Voyer, M. (2012b) Les soins sous contrainte des malades mentaux. In Psychocriminologie (eds J. L. Senon, G. Lopez \& R. Cario), pp. 295-308. Dunod.

\section{MENTAL HEALTHLAW PROFILE}

\title{
Mental health law profile on the Republic of Ireland
}

\author{
Anna Datta ${ }^{1}$ and Justin Frewen ${ }^{2}$
}

${ }^{1}$ GP Rural Track Training Scheme, Gilbert Bain Hospital, Lerwick, Shetland Islands, UK, email 828359@yahoo.com ${ }^{2}$ United Nations Consultant
This article provides a brief overview of the legislation that has been enacted in Ireland with respect to mental health, in particular the 2001 Mental Health Act. Although that Act was a positive step towards developing an Irish mental health service that protects the human rights of service users, a number of concerns remain, including issues related to consent and capacity, involuntary out-patient treatment and admission, the adversarial nature and timing of tribunals, and the lack of safeguards for voluntary patients.

\section{Background}

The Mental Treatment Act (MTA) was introduced in the Republic of Ireland in 1945 in response to strong public and professional pressure for mental health service reform and the introduction of involuntary admission procedures similar to those introduced in 1930 and 1932 in the UK and Northern Ireland, respectively (Kelly, 2008, pp. 65-66). The MTA introduced two new procedures for involuntary detention. The first stipulated that the patient must be examined by an authorised medical officer within 24 hours of an application for committal. Should the patient's need for involuntary committal be corroborated, he or she had to be examined by the district mental hospital's medical officer to confirm this. Detention would be for an indefinite period. The second procedure introduced was related to a new category of patient - the temporary patient - who could be detained for up to 6 months (Kelly, 2008, p. 66).

The MTA also introduced the concept of out-patient care for non-serious mental illness, a measure which it was hoped would reduce stigma, at least to some extent, with respect to mental ill health and district mental hospitals (Kelly, 2008, p. 67). It was amended by eight subsequent pieces of legislation up to and including the Health Act 1970.

\section{The 2001 Mental Health Act}

As the 20th century drew to a close, with growing recognition of the human rights of people with mental illness, pressure grew for new legislation (Nwachukwu et al, 2010, pp. 436-437). In July 2001, a Mental Health Act (MHA), regulating both adult and child psychiatry, was passed by the 